\section{0 indigenismo "Poema \\ de Chile \\ 9)}

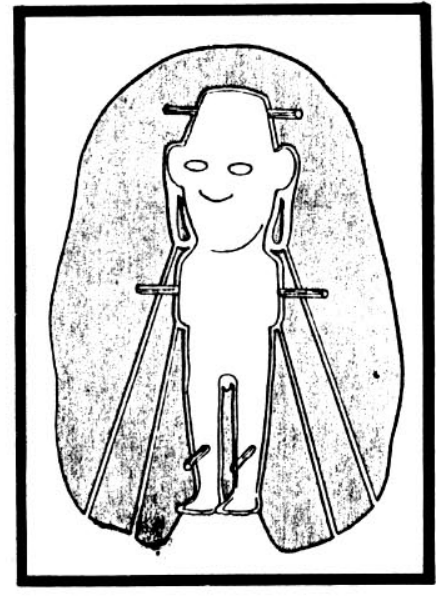

\title{
LIDIA NEGHMEECHEVERRÍA
}

Segundo Lotman e Uspenskij: "A cultura pode ser representada como um conjunto de textos; mas sob o ponto de vista do pesquisador é mais preciso falar da cultura enquanto mecanismo criador de um conjunto de textos visando a realização da cultura"(1). Nesse sentido, Gabriela Mistral (1889-1957), como assinalara Jaime Giordano em "Mistral: la ronda extraviada", apresenta um conflito na sua escrita "entre lo considerado bello por la tradición poética y 'lo nuestro"'(2). Seria uma pós-modernista que representaria uma sensibilidade crepuscular em relação ao movimento anterior: o modernismo. Jaime Concha assinalou, concretamente, em relação ao Poema, dois modelos operatórios, "uno procedente de la poesía chilena culta, otro que es derivación del acervo folclorico y de hábitos narrativos populares' '(3).

Sob nosso ponto de vista, essas posições não se contrapõem: complementam-se. Gabriela utilizou personagens-chaves na sua viagem pelo Chile: um menino e um animal. Este dado já foi assinalado por Concha entre os vários críticos que comentaram isso. Porém, convém perguntar-se por que escolheu essas personagens e não outras. Isto é, se esses tipos constroem um modelo cultural próprio, visto que eles articulariam "uma capacidade de condensar a experiência humana", assim como o frisaram Lotman e Uspenskij no ensaio "Sobre o mecanismo semiótico da cultura". Desse modo, haveriam signos caracterizadores dessa cultura.

Se analisarmos Poema de Chile (1967) sob esta perspectiva, observaremos que o menino indígena na sua relação com a falante não foi escolhido de maneira gratuita. Possui uma expressão que permite vislumbrar um comportamento. No poema inicial "Hallazgo" -, a voz poéticá insere a importância da companhia do indiozinho, apelativamente, empregando o diminutivo, talvez, com o intuito de sugerir ternura. Mas este é um uso próprio da linguagem coloquial chilena:

\footnotetext{
"Son muy tristes, mi chiquito, las rutas sin compañero: parecen un largo bostezo, jugarretas de hombre ebrio"

"Naciste en el palmo último de los Incas, Niño-Ciervo, donde empezamos nosotros $y$ donde se acaban ellos; y ahora tú me guías o soy yo la que te llevo iqué bien entender tú el alma y yo acordarme del cuerpo!"(4)
}

LIDIA NEGHME ECHEVERRÍA é professora-doutora de Literatura Hispano-Americana da Universidade de Såo Paulo.
1 "Sobre el mecanismo semiótico de la cultura". In J. Lotman, Escola de Tartu. Semiotica de la cultura. Trad. esp. de Nieves Mendes. Madrid, Cátedra, 1979, pp. 67-92.

Dioses, antidioses; ensayos criticos sobre poesla hispanoamericana. Concepción, Lar, 1987, pp. 25-30.

3 Gabriela Mistral. Madrid, Júcar, 1987, p.142.

4 As citaçōes de Poema de Chile são da ediçăo de Barcelona, Pomaire, 1967.

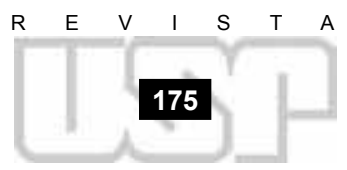




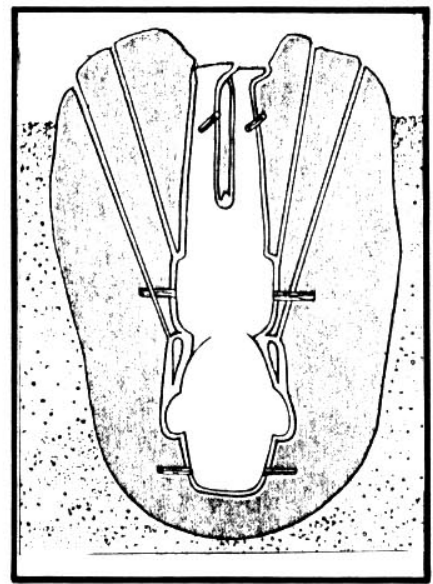

5 Ver ensaios reunidos por A. Calde rón: Materias. Santiago de Chile, Universitaria, 1978, pp. 94-9.

6 Buenos Aires, Los Incas, 1970, pp. 369-74.

7 Idem, ibidem, p. 374

8 Lima, Universo, 1968, pp. 38-9.

9 "Presencia de Gabriela Mistral. Notas de um Cuaderno de Memorias", in Anales de la Universidad de Chile. An̂o CXV, $n=106$. Segundo trimestre de 1957, pp. 282-92.

10 "Naturaleza americana y estilo en Gabriela Mistral", ibidem, p. 118.

11 Lotman e Uspenskij, op. cit., p. 85.

12 Idem, ibidem, pp. 86-7.

13 Walter Benjamin. Possie et revolution. Tradução francesa por Maurice Gandillac. Paris, Denöel, 1971, p. 212

14 Rosalba Campra. América Latina: la identidad y la máscara. México, Siglo Veintiuno, 1987, pp. 31-2.

15 Idem, ibidem, p. 32.

16 Lotman e Uspenskij, op. cit., p. 88.
Ressalta-se o caráter fronteiriço do menino e se cruza sua imagem com a do animal: "Niño-Ciervo". Prevalece o elemento cultural enquanto expressão, isto é, o texto condensa um conjunto de textos. Precisamos ter claro para descodificar estas passagens alguns dos ensaios em prosa da Mistral. Em "Algo sobre el Pueblo Quechua", datado de 20 de julho de 1947, Gabriela cita o Inca Garcilaso, Prescott e Boudin. Retoma alguma coisa do frisado por Boudin, ao assinalar: "Este pueblo sabio y niño conjuntamente primitivo y técnico, imperial y paclfico, bebió la fuerza de su régimen y la poesla de su vida Intima en dos manaderos que casi son uno mismo: religión astronómica y un sentido aristocrático, es decir, jerárquico, aplicado al bien común, el usufructo colectivo'(5). Para quem leu El Imperio Socialista de los Incas de Boudin, é evidente que Gabriela Mistral retomou suas idéias relativas aos incas. Na parte final do livro, Boudin ressalta uma expressão de García Calderón e insere como nome de um dos capítulos: "Um povo de meninos envelhecidos"(6). Mais adiante, explica o sentido dessa expressão. Assinala: "No son atraldos por las grandes ciudades, y no forman, como tantos otros miserables de nuestros patses, un proletariado urbano, salvo en Lima"'. (...) "Conducen sus rebaños de llamas como hactan sus abuelos, modulando en su flauta las canciones de otro tiempo. Su lengua es la de los antiguos amos, el quichua; sus costumbres son los de sus antepasados; su derecho consuetudinario subsiste al margen del derecho escrito; hasta su cristianismo no es más que un paganismo disfrazado" (7).

Pelos trechos citados de Poema de Chile, podemos verificar qui a voz poética, quando se refere a "mi chiquito" (meu pequenininho), que é o indiozinho, o considera como companheiro. Isto é, culturalmente, ela se "comprime" ou "estreita" dentro da cultura indigenista. For isso, insere um animal, elemento basilar para os índios do norte do Chile e para os incas. Não estabelece distinções de classe entre ser índio ou não sê-lo. Na vida real, sabemos por Ciro Alegría em Gabriela Mistral Intima, que ela falava de "mi abuelo indio". Acrescenta o escritor peruano: "Queria llamarle así. En realidad era mestizo"'(8). Atestamos que o fato de ter escolhido um menino índio e um animal são dados que patenteiam o modo de ser do texto. É possível verificar, claramente, o indigenismo, visto que sendo feita uma viagem na qual é descrito o Chile, tenta se modelizar o maior número possível de objetos conhecidos e desconhecidos para o leitor. É inegável que Gabriela Mistral reuniu um material enorme sobre o Chile, durante muitos anos. Laura Rodig marca esse interesse a partir de 1919, data em que a Mistral achava-se em Punta Arenas, no extremo sul do Chile ${ }^{(9)}$. Esta opinião é repetida por Jaime Concha no seu livro já citado. Quando Gabriela Mistral esteve em Puerto Rico, em 1948 , proferiu uma palestra, cujo conteúdo foi citado por Julio Molina Müller. O sentido é interessante, por frisar o caráter "não-finito" da cultura que ela percebe na dicotomia campo-cidade e que em Poema de Chile não existirá enquanto visão de mundo. $\mathrm{O}$ texto diz assim: "En cuantos palses he andado, vi siempre que el juego entre ciudady campo, el confluir de lo urbano con lo rural, la fertilización de lo uno por lo otro, ha hecho naciones más sanas, las más compactas y estables. Y vi también lo contrario las falsas 'unidades' en las cuales el campo se parece al jorobado o al manco que vive amargado de alimentar a sus parientes válidos, o sea las ciudades-patronas, engrasadas de ocio, o que en ajetreo inútil parecen ardillas bobas cogidas del fuego"(10).

A natureza, enquanto cultura, em Poema de Chile, revela um dinamismo social atravês do motivo da viagem. As três personagens, ao percorrer o Chile, comparam o lugar de seu nascimento com o que a paisagem lhes oferece no momento. Esta técnica fica clara em vários textos. Salientamos, pensando na análise: "Flores" (pp. 89-103), "Manzanos" (pp. 109-10) e "Araucanos" (pp. 195-7).

Em "Flores" esse contraste patenteia-se a partir das estrofes iniciais:

"- No te entiendo, mama, eso

de ir esquivando las casas

y buscando con los ojos

los pastos o las mollacas.

¿Nunca tuviste jardín

que como de largo pasas?

- Acuérdate, me crié

con más cerros y montañas

que con rosas y claveles

y sus luces y sus sombras

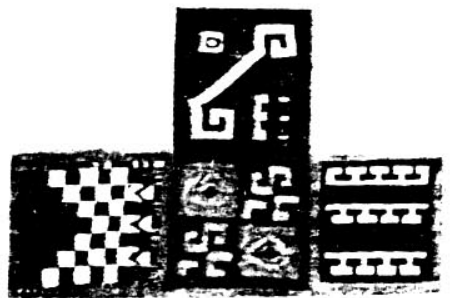

$\begin{array}{lllllll}R & E & V & \text { I } & S & T & A\end{array}$ 
aún me caen a la cara.

Los cerros cuentan historias

y las casas poco o nada."

Ora, o dinamismo da vida, o fato de ir esquivando casas e procurando animar a natureza ("los cerros cuentan historias"), porque ela abrange a base memorial desde o passado até o presente, torna a mobilidade da falante um dado natural sob o ponto de vista semiótico e cultural. Representa "a variação no modo de viver"(11) e a cultura dessa "mama" a diferencia de outros membros da sociedade chilena, porque, ao contrário do homem das cidades, ela salienta "cerros y montañas" diante de "rosas y claveles". "Cerros y montañas" na sua evocação memorial animam-se, contam histórias, ao passo que as casas destacam "poco o nada". A cultura, considerada como o não-finito, revela, lembrando do ensaio aludido por Julio Molina Müller, "la fertilización" da visão de quem fora criada "con más cerros y montañas" perante a mera artificiosidade da cidade: "rosas", "claveles", "casas". Isto é, a voz poética almeja ressaltar a cultura do natural, daquilo que estivera ali desde sempre, ou melhor, destaca-se o que o homem não deverá "retocar" no seu percurso. Isso insere um esclarecimento para o dinamismo da falante no poema. Ela tentará percorrer o Chile visando ensinar o leitor, entre múltiplas coisas, o que é o natural e onde poderia ser achado. Desse modo, quem conversa pretende "ampliar os conhecimentos de sua coletividade", como poderiam dizer Lotman e Uspenskij. E essa coletividade são os chilenos, seus leitores, seu povo, o universo de entes prestes a ler o livro. Por isso, o texto é universal e $\hat{e}$, ao mesmo tempo, indigenista. José María Arguedas também animou o dado natural em Los rlos profundos, romance peruano de 1958.

Em "Manzanos" há a inquietação pela louvação do estrangeiro perante um fruto da terra chilena. Existe a consciência de escrever "manzanos", estrutura invariável e única da realidade nacional.

“- ¿ Sabes tú? Los extranjeros
nos disputan lo que hubimos
pero cubren de alabanzas
la manzana que les dimos.
Plántalas en cuanto crezcas,
no estarás arrepentido.
- Mama, repite otra vez
aquello que has dicho,
que vamos a tener todos
st, st, huerta... o huertecillo.
Pero tanto tiempo dicen
eso mismo y no ha venido.
-Cree ahora a quien lo dice
la huerta viene en camino.
- ¿ Camino?
- St, ya se acerca.
Está llegando, mi niño."

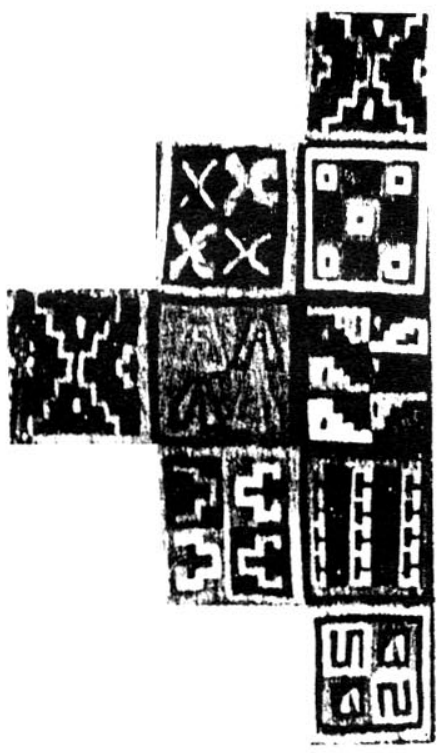

Apresenta-se uma tendência para a unificação interna. Supõe-se que todos os chilenos terão ou poderiam ter uma "horta", um pedaço de terra que vem "a caminho". Trata-se de uma tendência cultural. Segundo Lotman e Uspenskij, ela transfere-se para a "esfera ideológica"(12). Esta revisão social é vigorosa no romance indigenista em língua espanhola. No texto mistraliano, propõe-se, da mesma forma que o patenteara Boudin, uma espécie de direito "consuetudinário", que seria possível além do que fora escrito. Por isso, se alguém diz que teremos "huerta o huertecillo" é preciso acreditar, ou melhor, esperar que seja dessa maneira. Agindo assim, ilustra-se um tomar partido pelos homens despossuídos de seus bens. Segundo Boudin, para os cronistas da América e os escritores utopistas europeus, o sistema socialista dos incas significou um modeio. Gabriela, reativando esta visão da terra enquanto comunidade social, expôs uma posição revolucionária, se pensarmos na data em que ela poderia ter levado à escrita estes conteúdos ideológicos. Assim, verificamos que ela rompeu com o universo global do pensamento de sua época (pelo menos no relativo à sua pátria). Isto é valorizado por

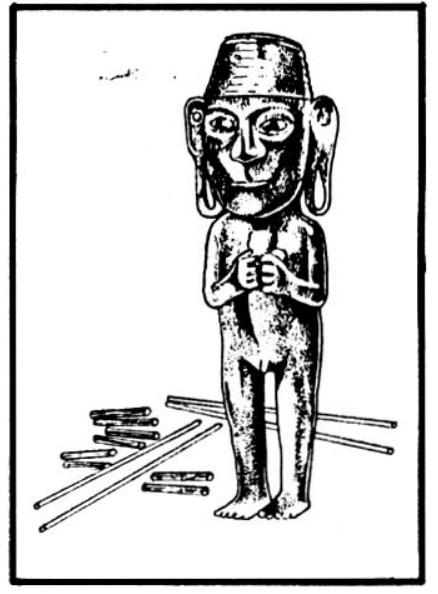

do pensamento de sua epoca (pelo menos no relativo à sua pátia). Isto e valorizado por 


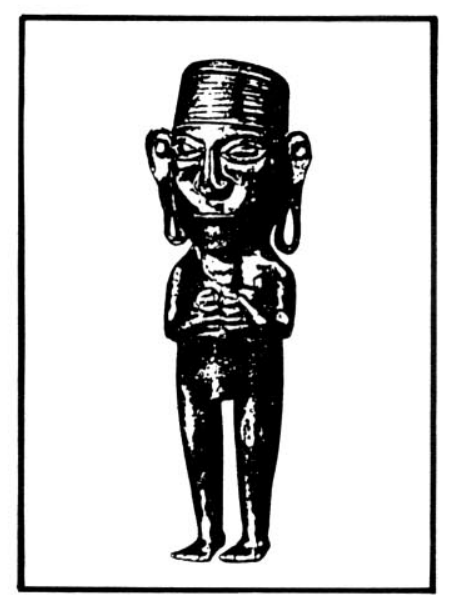

Benjamin, ao escrever sobre Gide(13), contemporâneo de Mistral. Assim, a escritora chilena patenteia a modernidade de sua escrita, uma vez que retoma um elemento do passado pré-colombiano e o torna um dado do presente, projetando-o para o futuro. Sabe-se que a Reforma Agrária foi uma realidade durante os governos democráticos que o Chile teve. Se lermos o texto no ângulo do nosso aqui e agora, deveremos achar verossímil o fato de a horta já se aproximar e que ainda está chegando.

Em "Araucanos" a falante vê passar uma araucana como um "fantasma". Há a denúncia da violência empregada contra o índio. Isso comove o acompanhante da voz poética. A falante pretende expor o modo de ser cultural desse povo, reconstruindo, a partir da memória histórica, o sistema do grupo social. Tenta tornar o indiozinho o destinatário da informação. Assim, ele terá de perceber a variação estrutural entre seu modo de ser e o próprio dos araucanos; mesmo no desfecho, estes, pelo fato de serem índios, irmanam-se como os incas.
“-Di cómo se llaman, dilo.
- Hasta su nombre les falta.
Los mientan 'araucanos'
y no quieren de nosotros
vernos bulto, otrnos habla.
Ellos fueron despojados,
pero son la Vieja Patria,
el primer vagido nuestro
y nuestra primera palabra.
Son un largo coro antiguo
que no más ré y ni canta."

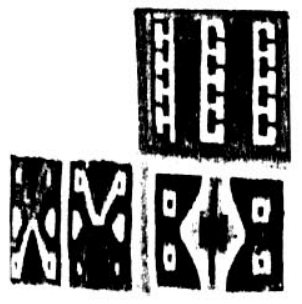

O texto verifica a desordem social da qual fora vítima o povo araucano. Recria-se, metonimicamente, a auto-alienação do araucano: "y no quieren de nosotros/vernos bulto, otrnos habla". Os primeiros habitantes do Chile foram esmagados pelos brancos. A poeta chilena, assim como Arguedas, desenvolve a temática de "la aspiración a una vida no escindida, afirmación de valores propios"'(14). Existe, assim, uma tendência a "uma constante renovação", assim como o frisaram Lotman e Uspenskij, ao expor um dos mecanismos do trabalho da cultura. Patenteia-se o sofrimento do araucano. Porém, ao mesmo tempo, a falante demonstra sua admiração por eles e a comunica para seu interlocutor: o menino índio.

"Nómbrala tú, di conmigo;

brava-gente-araucana.

Sigue diciendo: cayeron.

Di más: volverán mañana."

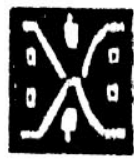

Através das gradações " "nómbrala", "Sigue diciendo" e "Di más", a voz poética cria variações nos conteúdos culturais. Os araucanos, estrutura cultural diversa, "volverán mañana". A mulher, que cruzara no início como sombra fantasmática, terá de voltar e reconhecer-se, idêntica, quer entre incas ou araucanos. Como se vê, a falante insere-se no indigenismo por fazer uma denúncia quanto às arbitrariedades toleradas pelos índios e por sua adesão aos valores autóctones desses povos. Parece encontrar forças para recuperar ainda: "la esperanza perdida después de cuatrocientos años de opresión $e$ injusticia"'(15), por isso estimula, imaginariamente, o encontro entre os diferentes índios americanos. Desse modo, o conteúdo cultural será um outro.

O último poema do livro denomina-se "Despedida". Reitera a possibilidade de ter amplificado a visão de mundo do indiozinho, companheiro de viagem e interlocutor:

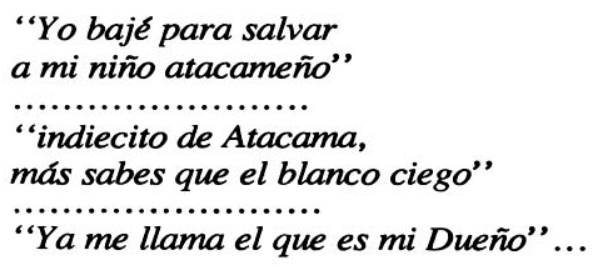

Em síntese: a voz poética maternal tem consciência de ter estimulado a mutação do menino. Ele já não será o mesmo depois desta viagem com a "mama". Terá compreendido, talvez, que para subsistir em meio de tanta tragédia é preciso unir sua "própria existência à existência de uma memória"(16), que ele não conhecia. Agora, a falante cumpriu sua missão na terra e pode atender ao apelo para a morte ou de quem a reclame. 